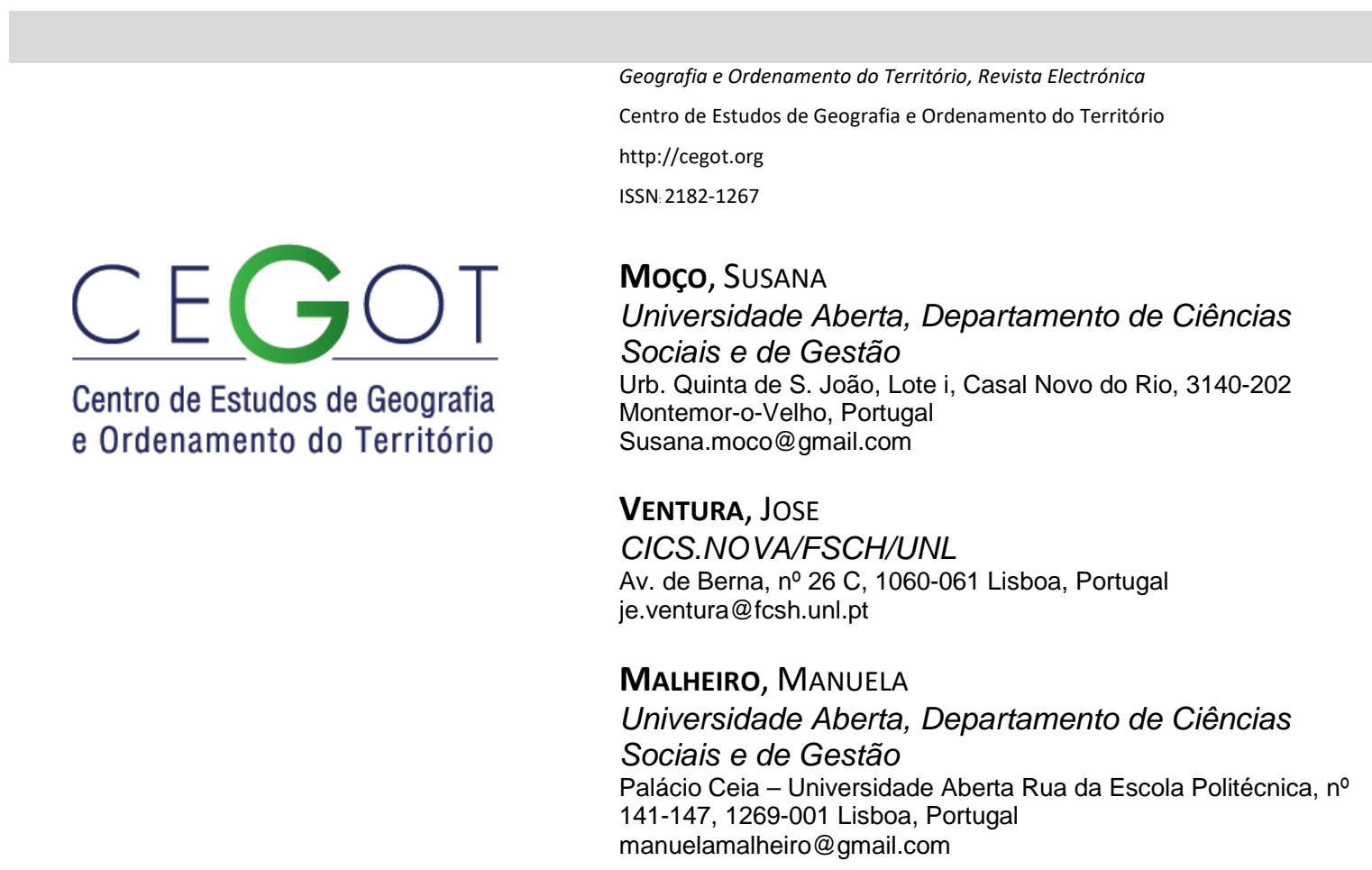

\title{
Alterações climáticas e educação ambiental - ferramenta pedagógica para a prática
}

Climate change and environmental education - pedagogy tool to practice

Referência: Moço, Susana; Ventura, José; Malheiro, Manuela (2016). Alterações climáticas e educação ambiental - ferramenta pedagógica para a prática. Revista de Geografia e Ordenamento do Território (GOT), n.o 10 (dezembro). Centro de Estudos de Geografia e Ordenamento do Território, p. 233-240, dx.doi.org/10.17127/got/2016.10.011

\section{RESUMO}

Perante as manifestações de mudança do sistema climático, é fundamental que todas as entidades, incluindo a escola, promovam a compreensão das problemáticas com que o mundo atual se defronta e tomem consciência da responsabilidade individual e da importância da ação coletiva no exercício de uma cidadania responsável. A educação para o Desenvolvimento Sustentável é imperativa, quer nos currículos dos anos de escolaridade iniciais, quer numa perspetiva de aprendizagem ao longo da vida em situações de ensino/aprendizagem formal e informal. Os jogos pedagógicos são uma opção estimulante e podem ser colocados em prática no quotidiano escolar tendo por base o rigor científico do tema. Abordar-se-á neste trabalho, a forma como através da criação e aplicação de um jogo pedagógico se poderá conduzir o aluno/jovem/cidadão a pensar, a levantar hipóteses e a consolidar o seu conhecimento consciencializando-se de que todos somos parte do problema e, em simultâneo, a solução do mesmo. 
Palavras Chave: Cidadania. Educação Ambiental. Alterações Climáticas. Desenvolvimento Sustentável.

\begin{abstract}
Given the demonstrations of changes of the climate system, it is fundamental that all entities, including school, promote the understanding of the problems the world is facing today and acknowledge the individual responsibility and the importance of collective action in the exercise of a responsible citizenship. Education for Sustainable Development is imperative both in the syllabus of the first school years as well as in a lifelong learning perspective, in formal and informal teaching/learning situations. Educational games are a stimulating option and can be used in daily school life, on the basis of scientific accuracy of the topic. In this work we will focus on how by creating and applying an educational game, you can lead a student/teenager/citizen to think, and strengthen his/her knowledge, acknowledging that we all are part of the problem and, at the same time, the solution to it.
\end{abstract}

Keywords: Citizenship. Environmental education. Climate change. Sustainable Development.

\title{
1. Introdução
}

Os jogos pedagógicos são uma opção estimulante, motivadora e apelativa que podem ser colocados em prática no quotidiano escolar de forma a favorecer o desenvolvimento motor, cognitivo e afetivo, facilitando a construção do conhecimento.

Abordar-se-á neste artigo, a forma como através da criação e utilização de um jogo pedagógico, se poderá conduzir o aluno/jovem a pensar, a levantar hipóteses, a criar estratégias ao mesmo tempo que socializa, consolida o seu conhecimento e se sensibiliza para a necessidade de adotar comportamentos ambientalmente sustentáveis no que respeita à problemática associada às manifestações de mudança do sistema climático.

\section{Metodologia}

Na criação do jogo foi utilizada a plataforma de desenvolvimento Scratch 2.0, um projeto do Lifelong Kindergarten Group do MIT Media Lab. Trata-se de uma linguagem de programação visual, muito simples e intuitiva que, por não ter custos adicionais, foi aquela que se 
considerou mais adequada à elaboração da ferramenta pedagógica. A aplicação é executável em qualquer computador que tenha esta versão do Scratch instalado ou através da plataforma online do mesmo (http://scratch.mit.edu/).

Não se considerando relevante a explanação do funcionamento e do ambiente de programação da aplicação, uma vez que se encontram inúmeros manuais, textos e tutoriais sobre o mesmo, dar-se-á relevância ao objetivo e às questões pedagógicas do jogo.

O jogo foi estruturado com base no tema das alterações climáticas, no conhecimento curricular dos programas escolares do 3ำ ciclo e secundário na área da Geografia, bem como, na necessidade de sensibilização e consolidação de conhecimentos dos alunos/jovens no que respeita às alterações climáticas, suas causas, consequências e algumas medidas de adaptação e mitigação.

A aplicação foi elaborada também com base no conceito do tradicional Jogo da Glória.

Foram elaboradas 24 questões de acordo com o objetivo estipulado (Tabela I). Os destinatários enquadram-se na faixa etária dos 12 aos 15 anos, portanto, alunos do 3 ciclo. Deu-se particular destaque a esta faixa etária dado que é neste nível de escolaridade que os programas de Geografia abrangem, de forma mais específica, esta temática. Tentou-se que o número de questões não fosse demasiado extenso para não desmotivar o aluno/jovem.

\section{Questões}

1) 0 que são as alterações climáticas?

2) O efeito de estufa é:

3) O principal gás com efeito de estufa de origem antrópica é o:

4) Uma das causas das alterações climáticas pode ser:

5) Uma das consequências das alterações climáticas pode ser:

6) O aquecimento global da Terra deve-se, entre outras causas, a:

\section{Respostas}

a) Resultam da mudança das estações do ano.

b) Representam mudanças significativas no clima.

c) Têm a ver com a mudança sazonal.

a) o aquecimento global.

b) um efeito natural da atmosfera terrestre.

c) crescimento de espécies vegetais em estufa.

a) metano.

b) enxofre.

c) dióxido de carbono.

a) diminuição da poluição.

b) aumento do efeito de estufa.

c) degelo.

a) aquecimento global da superfície terrestre.

b) aumento da biodiversidade.

c) aumento da poluição.

a) ao aumento de gases com efeito de estufa devido às atividades humanas.

b) ao aumento das áreas florestais. 


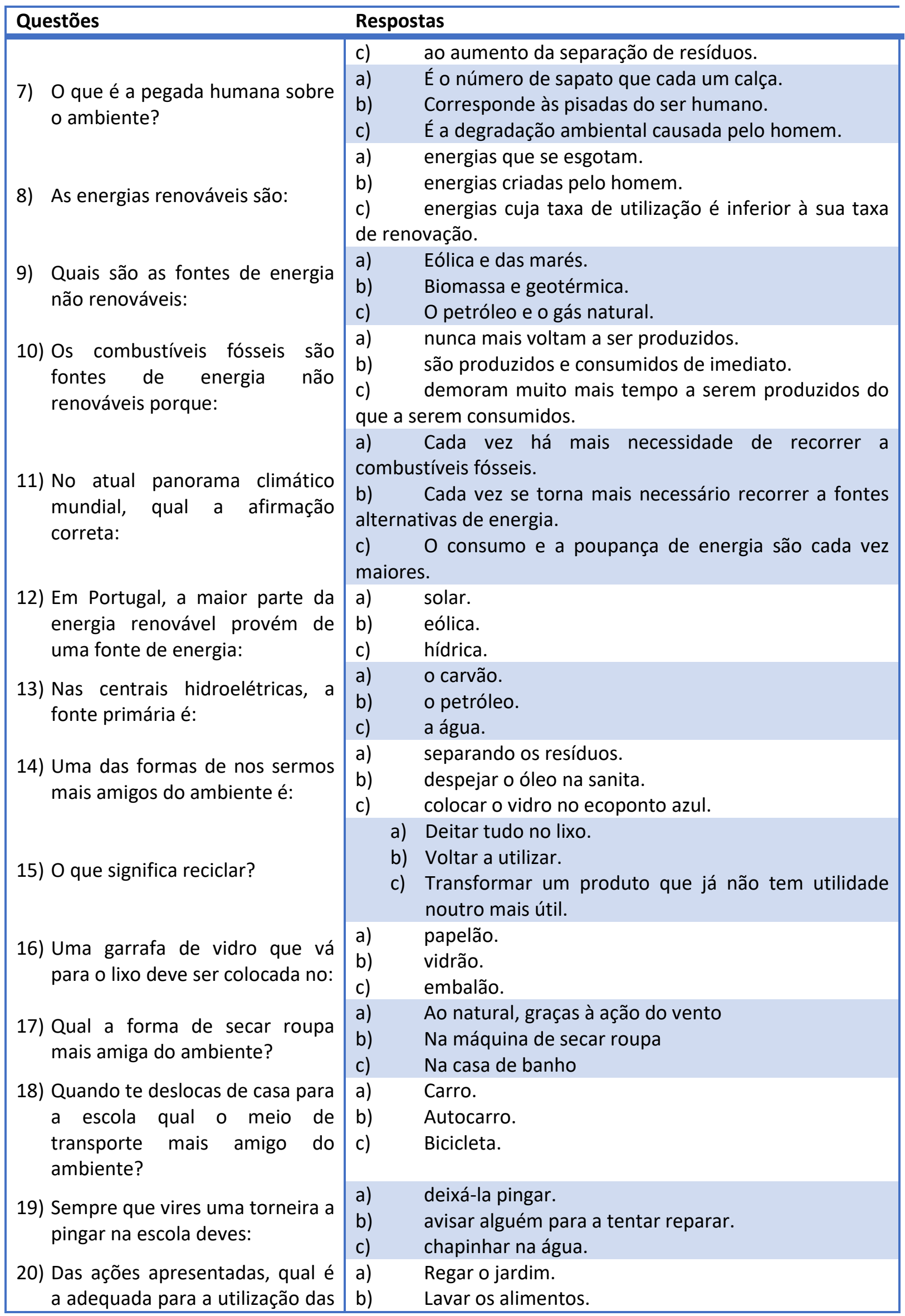




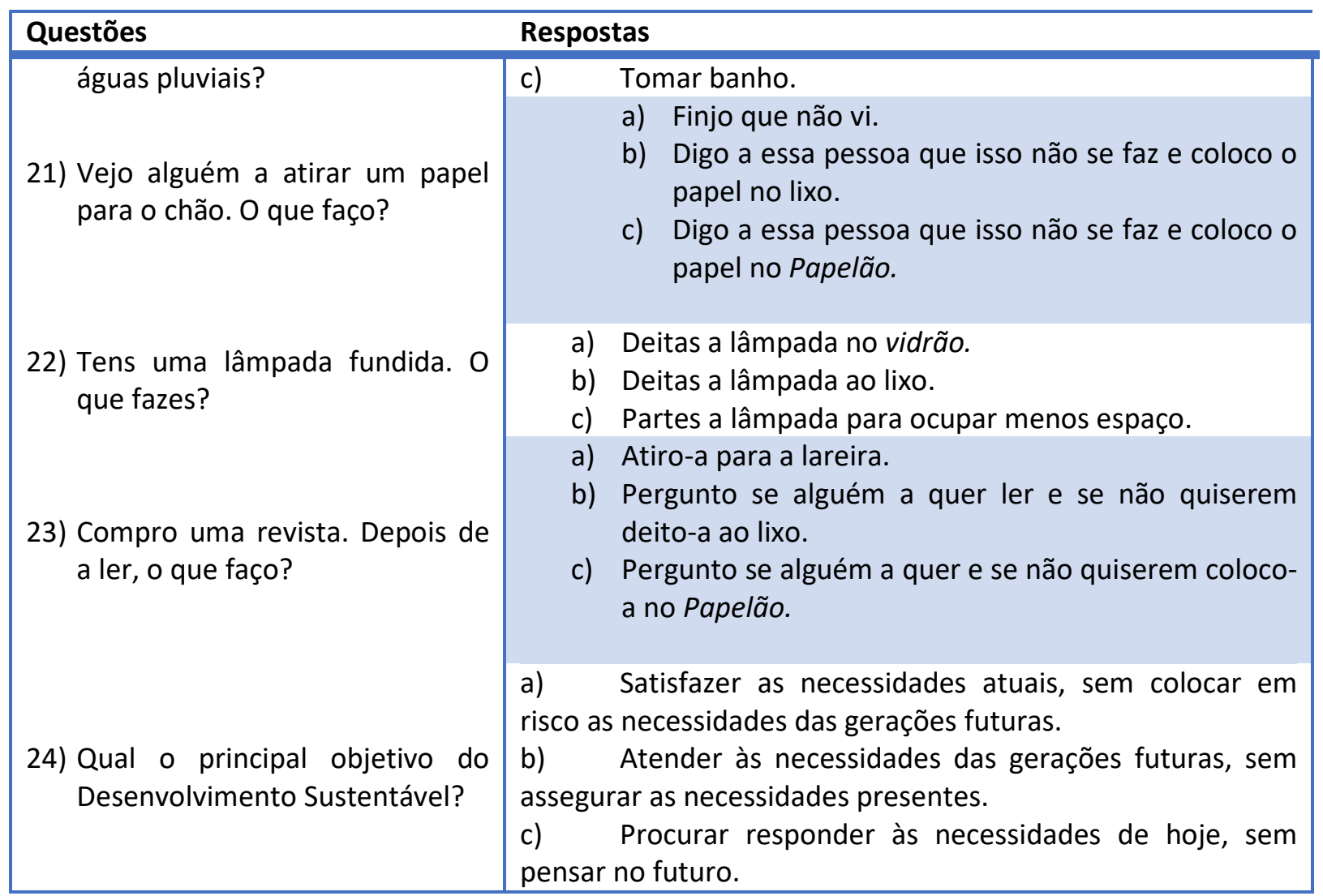

Tabela I - Questões e respostas utilizadas no jogo

As questões são complementares e estão diretamente relacionadas de forma temática ou metodológica. Pretende-se que todas possam ser utilizadas de forma isolada, ficando ao critério de quem as dinamize o seu enquadramento num quadro curricular no caso do ensino formal, ou a sua inserção noutros processos educativos e de dinamização socioambiental. No entanto, convém ressaltar que no seu conjunto, as mesmas são lançadas aos jogadores sem qualquer ordem distinta, ou seja, são escolhidas de forma aleatória de entre as 24 definidas, já que este procedimento é intrínseco às regras do jogo.

Quanto à elaboração das questões e respostas, procurou-se que estas fossem curtas pelo facto de a aplicação ter como pré-requisito a limitação de carateres por frase, possíveis de serem integralmente visualizados. 


\section{A estrutura do Jogo}

$\mathrm{Na}$ elaboração do jogo, relativamente às competências e valores a desenvolver, podem destacar-se a expressão oral, o estabelecimento de relações causa/efeito, a identificação de símbolos, a argumentação, a reflexão, a descrição, a síntese, a análise e gestão do tempo, a responsabilidade pessoal sobre o ambiente comum, a avaliação de alternativas a partir de diferentes perspetivas e o estabelecimento de relações causa/efeito.

Trata-se de um jogo de tabuleiro com 90 casas, podendo ser jogado, em simultâneo, no máximo, por 4 jogadores.

O jogo inicia com o lançamento do dado, partindo o jogador, escolhido de forma aleatória, pela própria aplicação (Figura 1).

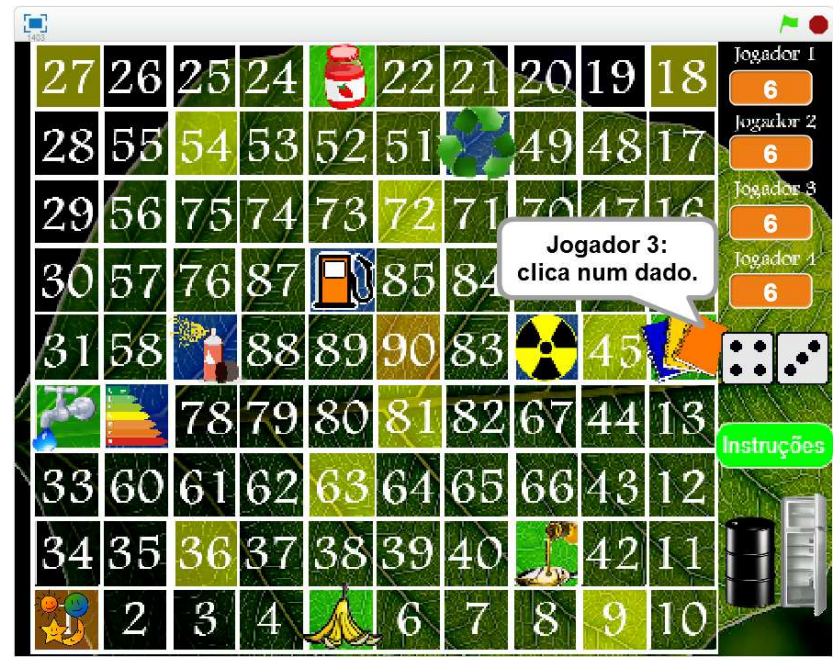

Figura 1 - Tabuleiro de jogo.

Dependendo do avanço das casas, os jogadores poderão receber multas e castigos nas casas esverdeadas ou azuladas, respetivamente, com um ícone. Caso o jogador atinja uma casa amarelada, será bonificado com o direito a passar à casa amarelada seguinte se tiver sucesso na resposta à pergunta que lhe será direcionada.

A cada jogador estará associada uma imagem que o representará e que é selecionada aleatoriamente pela aplicação. As imagens foram escolhidas tendo em conta elementos cosmográficos de forma tornar o jogo mais apelativo.

As multas e os castigos (Tabela II) foram elaborados de forma a poder levar o aluno/jovem a ponderar determinados comportamentos que são ambientalmente incorretos, sobretudo 
no caso das multas. Tentou-se que estas pudessem ser uma forma de estabelecer uma relação entre os comportamentos comumente adotados, o conhecimento e o que deve ser a ação responsável.

\begin{tabular}{|c|c|c|c|}
\hline \multicolumn{2}{|c|}{ Multas (Casas esverdeadas): } & \multicolumn{2}{|c|}{ Penalizações (Casas azuladas): } \\
\hline Casa 5 & Deitar lixo no chão: 2 euros & Casa 50 & $\begin{array}{l}\text { Não reciclar o lixo: Volta para onde } \\
\text { estavas }\end{array}$ \\
\hline Casa 14 & $\begin{array}{l}\text { Não aproveitar os cadernos de } \\
\text { um ano para o outro: } 2 \text { euros }\end{array}$ & Casa 59 & $\begin{array}{l}\text { Uso de eletrodomésticos de classe } \\
\text { inferior a A: Preso no frigorífico até } \\
\text { alguém o salvar }\end{array}$ \\
\hline Casa 23 & $\begin{array}{l}\text { Compra de produtos não locais: } \\
1 \text { euro }\end{array}$ & Casa 68 & $\begin{array}{l}\text { Central Nuclear: É eliminado pela } \\
\text { radiação }\end{array}$ \\
\hline Casa 32 & Desperdiçar água: 2 euros & Casa 77 & Aerossóis: Volta à casa 1 \\
\hline Casa 41 & Deitar óleo pela pia : 3 euros & Casa 86 & $\begin{array}{l}\text { Combustíveis fósseis: Fica preso na lata } \\
\text { de óleo até que outro lá caia e o } \\
\text { substitua }\end{array}$ \\
\hline
\end{tabular}

Tabela II - Multas e castigos

Os castigos foram elaborados de forma que o aluno/jovem se familiarize com alguma simbologia e sinalética no que respeita às questões ambientais.

Vence o jogador que chegar primeiro à última casa.

\section{Conclusão}

O jogo foi testado em três turmas do $8^{\circ}$ ano, sendo os resultados bastante satisfatórios. Os alunos demonstraram interesse e empenho, bastante espírito crítico havendo lugar para debates em torno de determinadas questões. Em suma, esta constatação permitiu perceber a utilidade desta ferramenta pedagógica que pode ser claramente utilizada por este nível de escolaridade e/ou por jovens com interesse pela temática. A aplicação encontra-se disponível em http://scratch.mit.edu/projects/30726278/. Convém, no entanto, salientar que o jogo pode e deve ser constantemente adaptado e melhorado. 
A criação desta ferramenta responde a algumas metas da educação ambiental, tornando mais acessível aos destinatários a compreensão da complexidade das alterações climáticas atenuando as fronteiras entre o que é conhecido e a ação responsável.

\section{Referências bibliográficas}

ALVES, F.A.M.B. Educação para o desenvolvimento sustentável em manuais escolares da área científica de ciências da natureza. Um estudo transversal (2 e 3 ciclos do Ensino Básico). Dissertação de Mestrado em Cidadania Ambiental e Participação, 2009, Universidade Aberta.

CARTEA, P.A.M. Conhece e valoriza as alterações climáticas - propostas para trabalhar em grupo. Fundación Mapfre e os autores, 2012.

FUNTOWICZ, S. \& RAVETZ, R. A new scientific methodology for global environmental issues. R. Constanza (org.) Environmental Economics, Columbia Un. Press, 1991, Nova lorque, pp. 137-152.

GAUDIANO, E.G. Educação Ambiental. 2005, Lisboa: Instituto Piaget.

MALHEIRO FERREIRA, M. Geographical education and citizenship: innovative practices. Helsinki Symposium, Commission on Geographical Education, 2001, pp. 271-273.

PEREIRA, R.B.C.T. Educação ambiental no ensino básico e secundário: concepções de professores e análise de manuais escolares. Dissertação de Doutoramento no Ramo de Estudos da Criança Área de Conhecimento Estudo do Meio Físico, Universidade do Minho, 2009, Instituto de Estudos da Criança.

PISA (2000) disponível em: http://www.gave.minedu.pt/np3content/?newsld=33\&fileName=conceitos literacia matematica.pdf, consulta em 23 de agosto de 2013. 